\title{
Global Environmental Challenges: Human-driven Oxidation of Reduced Sulfur Compounds from Geological Materials
}

\author{
Chuxia Lin \\ School of Environment and Life Science, University of Salford, \\ Salford, Greater Manchester M5 4WT, United Kingdom \\ C.Lin@salford.ac.uk
}

Human activities since the onset of Industrial Revolution in the early seventeenth century have caused dramatic changes to the Earth's surface environments. While the human living standard, as measured by real income per capita, has been improved as a whole due to technological progress, the environmental degradation associated with such economic growth is widespread, threatening the sustainable development of mankind.

Large-scale environmental acidification is one of the striking consequences of industrial production. Burning of sulfurcontaining fossil fuels causes acid rain; Mining activities result in acid mine drainage; and reclamation of coastal floodplain leads to formation of acid sulfate soils and the resulting acid discharge into estuaries. In this presentation, focus will be placed on the impacts of environmental acidification on ecosystems and human well-being on a global scale. 